\title{
University professors' mental and physical well-being during the COVID-19 pandemic and distance teaching
}

\author{
Khader A. Almhdawi ${ }^{\mathrm{a}, *}$, Donia Obeidat ${ }^{\mathrm{a}}$, Saddam F. Kanaan ${ }^{\mathrm{b}}$, Nupur Hajela $^{\mathrm{c}}$, Mohammad Bsoul ${ }^{\mathrm{d}}$, \\ Alaa Arabiat ${ }^{\mathrm{e}}$, Alza Alazrai ${ }^{\mathrm{a}}$, Hanan Jaber ${ }^{\mathrm{a}}$ and Hassan Alrabbaie ${ }^{\mathrm{a}}$ \\ ${ }^{a}$ Department of Rehabilitation Sciences, Faculty of Applied Medical Sciences, Jordan University of Science and \\ Technology, Jordan \\ ${ }^{\mathrm{b}}$ Department of Rehabilitation Sciences-Physical Therapy, Faculty of Applied Medical Sciences, Jordan \\ University of Science and Technology, Jordan \\ ${ }^{\mathrm{c}}$ Department of Physical Therapy, California State University - Fresno, Fresno, CA, USA \\ ${ }^{\mathrm{d}}$ Department of Computer Science and Applications, Faculty of Prince Al-Hussein Bin Abdullah II for Information \\ Technology, The Hashemite University, Zarqa, Jordan \\ ${ }^{\mathrm{e}}$ Family Medicine Specialist, Department of Family Medicine, The Jordanian Ministry of Health, Jordan
}

Received 28 November 2020

Accepted 13 May 2021

\begin{abstract}
.
BACKGROUND: Strict strategies including lockdowns and working from home were adopted worldwide during the coronavirus (COVID-19) pandemic. University professors suddenly shifted to work from home adopting distance teaching. OBJECTIVES: This study aimed to investigate Health-Related Quality of Life (HRQoL) and its associated occupational and health factors during COVID-19 among university professors.

METHODS: A cross-sectional design targeted university professors of all majors in Jordan. The study self-administered survey included demographics and lifestyle data, 12-item Short Form health survey (SF-12), Depression Anxiety Stress Scale (DASS 21), professor' evaluation of distance teaching, Neck Disability Index (NDI), and International Physical Activity Questionnaire (IPAQ). Descriptive analyses were conducted to demonstrate primary outcome measures data. Factors associated with HRQoL were determined using a multiple variable linear regression analysis.

RESULTS: A total of 299 university professors successfully completed the study. Participants' SF-12 physical health component score was $74.08( \pm 18.5)$ and $65.74( \pm 21.4)$ for mental health component. Higher depression, stress, neck disability, and weight change were significantly associated with lower HRQoL level. While higher satisfaction with distance teaching, health self-evaluation, and work load change were significantly associated with higher HRQoL level. The regression model explained $66.7 \%$ of the variance in professors' HRQoL ( $\mathrm{r} 2=0.667, F=82.83, P<0.001$ ).

CONCLUSIONS: Jordanian university professors demonstrated good HRQoL and mental health levels during COVID-19 lockdown. Factors associated with professors' HRQoL should be considered by academic institutions in determining the best occupational setup of teaching activities in future pandemics.
\end{abstract}

Keywords: Occupational stress, professors, health-related quality of life, mental health, stress, depression

\footnotetext{
*Address for correspondence: Dr. Khader Almhdawi, Department of Rehabilitation Sciences, Faculty of Applied Medical Sciences, Jordan University of Science and Technology, PO Box
}

3030, Irbid 22110, Jordan. Tel.: +962 27201000 26939; Fax: +962 7201087; E-mail: Khader@just.edu.job.; ORCID: 00000001-8906-6994. 


\section{Introduction}

In February 2020, the World Health Organization (WHO) declared the coronavirus (COVID-19) a pandemic [1]. Lockdowns, curfews, quarantines, social distancing, and work from home have been applied in many countries worldwide including Jordan [2, 3]. As a result, public and private universities had to fully adopt distance learning. Such strict procedures adopted to ensure publics' health safety (particularly if lasted for long durations) might be associated with increased levels of stress, confusion, anger, boredom, and financial stress [4].

Even in normal situations, university professors are subjected to serious levels of stressors related to their academic load [5-7]. Mental health symptoms (might be increased in lockdowns) such as depression, anxiety, and stress are also statistically linked with poor levels of HRQoL [8-11]. Teaching from home (distance teaching) is not new in academia $[12,13]$. However, the academic world has never experienced such an outbreak required sudden full conversion into distance teaching. Increased distance teaching activities could be associated with increased duration of computer use as compared to regular teaching, which might expose professors to more stress and neck pain [14-16]. During lockdowns, university professors might also demonstrate decreased levels of physical activity and quality of life as well as increased level of mental health symptoms [17-19].

Work-related Musculoskeletal Disorders (WMSDs) have been associated with increased office work and using computers [20, 21]. An increase in daily use of computers along with poor ergonomics might lead to an increase in the risk of WMSDs and its associated symptoms [22, 23]. Studies found that 55\% of university faculty members are affected greatly by WMSDs, with neck pain to be the most prevalent WMSDs (53.5\%), followed by low back pain (43.3\%) [20, 24]. Moreover, depression, anxiety, and poor quality of life were reported more frequently among individuals with neck pain [25].

Changes in the work environment might have negative effects on professors' well-being. It appears that academic job context characteristics such as available resources and job demands are significantly associated with levels of stress and job satisfaction [21]. For example, higher levels of stress are often associated with hectic academic workload as professors reported being unable to spend more time with students to address their concerns and having poor task management [26]. It will be interesting to evaluate university professors' health and well-being as their work demands and context were changed due to fully working from home.

There are a limited number of studies that investigated professors HRQoL and well-being [27-29]; and there no previous studies which investigated professors' HRQoL level and its associated factors during COVID-19. Globally, professors were affected by many strict procedures adopted in responses to COVID-19; and were subjected to changes in the context of their job by enforcing a sudden shift into $100 \%$ online teaching.

The purpose of this study was to examine the level of HRQoL during online teaching and to identify its occupational and health-related predictors during COVID-19 lockdown among professors in Jordan. This study appears to be well warranted and might help in better understanding academia under extraordinary stressful situations and to enhance future academic emergency planning.

\section{Methods}

\subsection{Design}

A cross-sectional design using a self-administered questionnaire study was conducted.

\subsection{Sample}

The study targeted professors who were working at public and private Jordanian universities of all academic majors. Sample size calculation was conducted using G-power (with an average of 15 predictors and effect size of 0.15) determined the minimum sample size needed to guarantee statistical power of $95 \%$ was 139 participants [30]. A convenient sample of 299 faculty members were recruited. Inclusion criteria included being a male or female between 24-75 years old, a full-time employment in one of the Jordanian public or private academic institutions, and being involved in teaching online during COVID-19 pandemic. Faculty members who were on academic leaves, or had no teaching load, or cannot communicate in Arabic were excluded.

\subsection{Outcome measures}

The study researchers developed an Arabic selfadministered questionnaire including: consent form, demographic and lifestyle information, and the 
evaluation of the online teaching process. Study participants evaluated their experience with online teaching using a 15-statement Likert scale scored as the following: $1=$ strongly disagree, $2=$ disagree, $3=$ Neutral, $4=$ agree, $5=$ strongly agree. Mean scores of each statement and average mean score of all statements were calculated.

The study survey also included Arabic versions of the following valid and reliable standardized questionnaires:

1- Medical Outcomes Study Short Form (SF-12): This measure was used to assess the level of HRQoL. The test includes questions rating individual general health such as: "In general, would you say your health is" and questions related to activity limitation such as: were your ability of "climbing several flights of stairs" limited? The measure is valid and reliable and has a total score (SF-12 total, a physical component score (PCS), and a mental component score (MCS). A higher score in SF-12 indicates a better HRQoL level [31, 32].

2- Depression Anxiety Stress Scale (DASS): This measure was used to assess the level of mental health symptoms among study participants. The measure has three subscales covering depression, anxiety, and stress and is considered valid and reliable. The measure uses a frequency rating scale (never - all the time) to rate statements such as "I was aware of dryness of my mouth" and "I found it difficult to relax": A higher DASS score suggests a higher level of mental health symptoms. The cut-off points indicating the presences of mild or greater mental health symptoms are 10 for depression, 8 for anxiety, and 15 for stress [33-35].

3- Neck Disability Index (NDI): This is a valid and reliable questionnaire used to assess the effect of neck pain on the performance of daily activities. The measure items include questions rating "pain Intensity "and functional activity limitations due to neck pain such as "reading" and "lifting". NDI score ranges from 0-50, where a higher score indicates more neck disability [36, 37].

4- The International Physical Activity Questionnaire (IPAQ) is a valid measure for a physical activity level categorizing it into high, moderate, and low. An example of the test items is: "During the last 7 days, on how many days did you do vigorous physical activities like heavy lifting, digging, aerobics, or fast bicycling? [38-41].

Before launching the final version of the survey, the initial version was reviewed by an expert panel and was piloted on 10 professors for clarity. Pilot participants' reported that the average time needed to complete the survey was about 20 minutes. All of the pilot participants' feedback about the survey was positive and they reported no difficulties in understanding the survey questions.

\subsection{Procedures}

Study data was collected between March and May 2020. The questionnaire was sent to participants online using Google forms. The link to the questionnaire was posted on various social media applications and popular web pages at Jordanian universities. Potential participants signed an electronic consent form approved by Jordan University of Science and Technology Institutional Review Board (IRB) approval \# 68/132/2020. Then participants filled the anonymous questionnaire and assessment scales. Study data was coded and logged into Excel spreadsheets in preparation for statistical analyses.

\subsection{Statistical analyses}

Data was analyzed using IBM SPSS statistics version 23 (SPSS, Inc., Chicago, IL, USA). Descriptive statistics including means and standard deviations, or frequencies and proportions were calculated to describe data. Binary correlations between collected factors and HRQoL scores were calculated. In the case when a correlation $p$-value was $<0.2$ for a factor, this factor was inserted in the regression analysis [42]. Level of HRQoL statistical associations with study factors data were assessed by a multiple linear regression using stepwise feature. A $p$-value $<0.05$ was considered significant in all of the analyses.

\section{Results}

In total, 299 professors agreed to participate and successfully completed the survey. About 203 $(67.9 \%)$ of the participants were males and about $96(32.1 \%)$ were females. The overall participants' mean age was 46.15 years $( \pm 9.43)$ and their mean experience was $13.4( \pm 8.67)$ years. About 110 (36.8\%) of participants were of medical majors and 
Table 1

Participants' characteristics and lifestyle during COVID-19

\begin{tabular}{ll}
\hline Characteristic & Mean (SD) or n (\%) \\
\hline Age: years & $46.15(9.43)$ \\
Gender & Male: $203(67.9 \%)$ \\
& Female: $96(32.1 \%)$ \\
Experience years & $13.4(8.67)$ \\
Academic major & Computer sciences or \\
& Engineering: $70(23.4 \%)$ \\
& Medical professions: $110(36.8 \%)$ \\
& Other: $119(39.8 \%)$ \\
Academic workload & Decreased: $55(18.4 \%)$ \\
change during COVID-19 & Same: $47(15.7 \%)$ \\
& Increased: $197(65.9 \%)$ \\
Cigarette smoking & No: 249 $(83.3 \%)$ \\
& Yes: $50(16.7 \%)$ \\
Water pipe smoking & No: $254(84.9 \%)$ \\
& Yes: $45(15.1 \%)$ \\
Diet self-evaluation & Unhealthy: $12(4.0 \%)$ \\
& Sort of healthy: $204(68.2 \%)$ \\
Weight changes during & Healthy: $83(27.8 \%)$ \\
COVID-19 & Decreased: $37(12.4 \%)$ \\
& Same: $158(52.8 \%)$ \\
& Increased: $104(34.8 \%)$ \\
\hline
\end{tabular}

n: number, SD: Standard deviation.

$70(23.4 \%)$ of computer sciences or engineering. Regarding workload during COVID-19, 197 (65.9\%) of the professors reported that their work increased while $55(18.4 \%)$ reported a decrease. Table 1 shows the general characteristics and lifestyle of participants during COVID-19.

Study results also demonstrate that participants had relatively good levels of HRQoL as measured by SF-12 which has a maximum score of 100 for each of its total, MCS, and PCS scores [31, 32]. The overall mean of SF-12 physical health subscore was 74.08 ( \pm 18.5 ), while the overall mean of SF-12 mental health subscore was $65.74( \pm 21.4)$ with SF-12 total mean $69.22( \pm 18.4)$. Furthermore, Depression symptoms (a score of 10 or higher) were found in $30.6 \%$ of professors with an overall normal level mean score of $6.86( \pm 6.9)$. Anxiety symptoms (a score of 8 or higher) were found in $18.7 \%$ of the participants with an average normal level mean score of $3.99( \pm 6.2)[33,34]$. Results have also indicated stress symptoms (a score of 15 or higher) in 17.1\% of the participants with an average normal level mean score of $8.34( \pm 8.8)$. About $176(58.9 \%)$ of the professors had low physical activities as measured by IPAQ-SF with overall total physical activity MET mean of $1167.0( \pm 1914.9)$ [38-40]. Finally, the overall mean of neck disability measured by NDI was $6.53( \pm 6.3)$ suggesting a mild neck physical disability. Table 2 includes the health characteristics of the participants during the pandemic.
Table 2

Health characteristics of participants

\begin{tabular}{lc}
\hline Characteristic & Mean (SD) or $\mathrm{n}(\%)$ \\
\hline DASS depression score & $6.86(6.9)$ \\
DASS anxiety score & $3.99(6.2)$ \\
DASS stress score & $8.34(8.8)$ \\
SF12 total score & $69.22(18.4)$ \\
SF12 PCS & $74.28(18.5)$ \\
SF12 MCS & $65.74(21.4)$ \\
IPAQ total & $1167.0(1914.9)$ \\
NDI & $6.53(6.3)$ \\
\hline
\end{tabular}

$\mathrm{n}$ : number, SD: Standard deviation, DASS: Depression Anxiety Stress Scale, SF-12:12-item Short-Form Health Survey, MCS: Motor Component Summary, PCS: Physical Component Summary, IPAQ: International Physical Activity Questionnaire, NDI: Neck Disability Index.

Table 3

COVID-19 effects on participants' academic activities

\begin{tabular}{|c|c|c|}
\hline Characteristic & \multicolumn{2}{|l|}{ Mean (SD) or $\mathrm{n}(\%)$} \\
\hline $\begin{array}{l}\text { COVID- } 19 \text { affected my daily } \\
\text { activities balance* }\end{array}$ & \multicolumn{2}{|c|}{$2.68(0.8)$} \\
\hline $\begin{array}{l}\text { COVID-19 negatively } \\
\text { affected my research* }\end{array}$ & \multicolumn{2}{|c|}{$2.62(0.9)$} \\
\hline $\begin{array}{l}\text { Number of online courses } \\
\text { taught prior to COVID-19 }\end{array}$ & \multicolumn{2}{|c|}{$1.11(1.5)$} \\
\hline $\begin{array}{l}\text { Number of online courses } \\
\text { being taught during } \\
\text { COVID-19 }\end{array}$ & \multicolumn{2}{|c|}{$2.94(1.3)$} \\
\hline $\begin{array}{l}\text { Daily time needed to prepare } \\
\text { for online courses during } \\
\text { COVID-19 }\end{array}$ & \multicolumn{2}{|c|}{$4.40(2.5)$} \\
\hline \multirow{3}{*}{$\begin{array}{l}\text { Preferred position for online } \\
\text { teaching activities }\end{array}$} & Table and chair & $190(63.5 \%)$ \\
\hline & Living room & $94(31.4 \%)$ \\
\hline & Bed or floor & $15(5.0 \%)$ \\
\hline
\end{tabular}

*Scored using a 5-point Likert scale ( $1=$ strongly disagree, 2 disagree, $3=$ neutral, $4=$ agree, $5=$ strongly agree).

Participants were also surveyed about the effect of COVID-19 on their academic activities. As listed in Table 3, the results show no change in the professors' daily life activities balance, no negative impact on research activities, an increase in online courses, and an average of 4.4 hours/day as the time needed to manage online teaching activities.

Participating professors have also evaluated the online teaching process responding to 15 Likert scaled of positively stated statements with scores from 1 to 5 , with 1 being extremely disagree and 5 being extremely agree. A score of 3 indicates being neutral about the scale statement. The used 15-item Likert scale to evaluate professors' satisfaction with the online teaching process during COVID-19 proved to be valid and internally consistent as Cronbach's 
Table 4

Participants' average evaluation of online teaching activities using a 5-point Likert scale ( 1 = strongly disagree, 2 disagree, $3=$ neutral, $4=$ agree, $5=$ strongly agree)

\begin{tabular}{llc}
\hline & Characteristic & Mean (SD) \\
\hline 1. & Our online teaching is of a high quality & $3.60(0.9)$ \\
2. & Online teaching is as beneficial as traditional & $2.70(1.1)$ \\
3. & Online teaching is beneficial for theoretical courses & $3.67(0.9)$ \\
4. & Online teaching is beneficial for laboratory courses & $1.86(0.8)$ \\
5. & Online teaching is beneficial for field training courses & $1.70(0.9)$ \\
6. & Students put enough efforts to utilize online teaching & $2.68(1.0)$ \\
7. & Students communicate enough and regularly with professors & $3.11(1.1)$ \\
8. & Internet quality is good enough for online teaching & $3.28(1.2)$ \\
9. & Online teaching assessment system is clear and fair & $2.52(1.1)$ \\
10. & Students easily understand my online teaching instructions & $3.52(0.9)$ \\
11. & My online teaching activities are regular and announced in advanced & $3.81(0.9)$ \\
12. & I don't face technical issues during online teaching & $3.40(1.2)$ \\
13. & I get enough IT and technical support & $3.39(1.1)$ \\
14. & Online teaching requires less efforts than traditional & $2.00(1.0)$ \\
15. & I wish to adopt online teaching in more future courses after COVID-19 & $2.99(1.2)$ \\
16. & Average of satisfaction with online teaching & $2.94(0.6)$ \\
\hline
\end{tabular}

Table 5

Multivariable regression analysis associated factors with health-related quality of life measured by SF-12 survey total score

\begin{tabular}{|c|c|c|c|c|}
\hline Factor & $\beta$ coefficient & $95 \% \mathrm{c}$ & nterval & $P$-value \\
\hline Depression & -0.93 & -1.23 & -0.63 & $P<0.001$ \\
\hline Health self-evaluation & 6.32 & 3.72 & 8.91 & $P<0.001$ \\
\hline Neck Disability Index scale score & -0.56 & -0.81 & -0.29 & $P<0.001$ \\
\hline Satisfaction average with online teaching & 3.94 & 1.95 & 5.91 & $P<0.001$ \\
\hline Stress & -0.48 & -0.73 & -0.23 & $P<0.001$ \\
\hline Work change last month & 2.81 & 1.22 & 4.39 & $P=0.001$ \\
\hline Weight change last month & -2.22 & -4.11 & -0.31 & $P=0.022$ \\
\hline
\end{tabular}

alpha coefficient was 0.874 . Overall, professors were almost neutrally satisfied $(2.94 \pm 0.6)$ with the online teaching activities during COVID-19. It was reported by the professors that the online teaching they were providing was of high quality, but fits more with theoretical teaching rather than laboratory-based and training courses. Table 4 lists the online evaluation statements and mean scores of professors' responses to each statement.

Table 5 shows the results of the multivariable linear regression. The results showed that depression $(\boldsymbol{\beta}=-0.93$ [95\%CI -1.23 to -0.63$], P<0.001)$, Neck Disability Index scale $(\boldsymbol{\beta}=-0.56[95 \% \mathrm{CI}-0.81$ to-0.29], $P<0.001)$, stress $(\boldsymbol{\beta}=-0.48$ [95\%CI -0.73 to -0.23$], P<0.001$ ), and weight change last month ( $\boldsymbol{\beta}=-2.22$ [95\%CI -4.11 to -0.31 ] $P<0.05)$ were significant negative predictors of HRQoL. On the other hand, health self-evaluation $(\boldsymbol{\beta}=6.32$ [95\% CI 3.72 to 8.91$], P<0.001)$, average of satisfaction with online teaching $(\boldsymbol{\beta}=3.94$ [95\% CI 1.95 to 5.91], $P<0.001)$, and work change last month $(\boldsymbol{\beta}=2.81$ [95\%CI 1.22 to 4.39 ], $P=0.001$ ) were significantly positive predictors of HRQoL. The regression model explained $66.7 \%$ of the variance in professors' HRQoL (r2 =0.667, $F=82.83, P<0.001$ ).

\section{Discussion}

The main goal of this study was to investigate the level of HRQoL and identify its associated factors after sudden adoption of online teaching among university professors in Jordan. This study might help to improve our understanding of academia under extraordinary stressful situations to enhance future academic emergency planning. To the best of our knowledge, this is the first study of its kind to evaluate professors' level of HRQoL and its predictors during COVID-19 and sudden shift to online teaching. This study data might be utilized in future comparative studies and to inform academic institutions decisions.

Work stress and psychological related factors among university professors are thought to have 
cultural differences among different communities [18]. Although HRQoL was never studied among Jordanian professors, the current study participants' HRQoL during COVID-19 (measured by SF-12 total) mean score of 69.22 is considered good and probably better than the general adult population around the world [43-46]. The average mean scores of depression, anxiety, and stress indicated normal levels (absence of symptoms) in all of these mental health symptoms. However, a mild level or higher of depression, anxiety, and stress were found in $17.1-30.6 \%$ of participants. Additionally, this study identified health factors that are significantly associated with HRQoL during online teaching activities which included depression, stress, neck pain, weight change, work change, online teaching satisfaction, and health self-evaluation. The produced regression model was statistically significant and powerful as it was able to explain about $66.7 \%$ of the variance in professors HRQoL.

This study is the first to examine the link between the increase of neck pain during lockdown due to online teaching. The change in the work environment (i.e. working from home) caused $36.5 \%$ of participants to reporting using poor ergonomics while delivering the courses online contents. This finding is substantiated by previous studies which showed poor ergonomics is associated with neck pain and that might lead to decreasing HRQoL [22, 23, 25].

Many studies documented the psychological impact during lockdown with very few targeted university professors [47-49]. A recent review stated that that there were significant and long standing adverse psychological effects such as post-traumatic stress disorders associated with COVID-19 pandemic particularly with longer quarantine duration, financial loss, greater fears of infections, and lack of infection control supplies. [4]. These findings are in line with our results. Moreover, professors were reported in other studies to have an increased stress level due to transferring to online teaching [4].

One interesting finding was that increased work load and increased satisfaction with online teaching were significantly associated with higher levels of HRQoL. One possible explanation for this finding is that professors spent more time preparing for their online teaching might have generated better teaching quality and got better satisfaction with their online teaching., Spending more time improving online teaching quality could have increased professors' self-efficacy and probably enhanced their HRQoL [50-52].
In this study, HRQoL was significantly and negatively associated mainly with mental health symptoms and neck pain. These findings were not surprising and matched other findings in the literature $[35,53]$. Although no studies were found on professors' HRQoL during the lockdown, with the high levels of mental health symptoms and neck disability, it was predicted to have worsened HRQoL during the pandemic.

\section{Limitations and future directions}

One of the limitations of this study was that it adopted an online survey which could have limited generalizability. The study also had no comparisons between HRQoL prior to the pandemic and during it which prevent extracting conclusions related to COVID-19 effects on the population quality of life and its predictors. Additionally, there was a higher representation of males in the sample than females. However, in Jordan there are more male professors than female. Future studies should consider having larger samples from multiple countries. Future studies are also encouraged to design effective interventions to enhance university professors' quality of life and wellbeing under normal and extraordinary situations including pandemic and other types of emergencies.

\section{Conclusion}

This study has established that the level of HRQoL among Jordanian professors was relatively good, and that they were experiencing low levels of mental health symptoms during COVID-19. The study revealed that neck pain, depression, and stress were negatively associated with university professors' HRQoL level. Finally, high health self-evaluation, and satisfaction with online teaching and work conditions during lockdown were associated with higher HRQoL. COVID -19 is an ongoing pandemic and the findings from similar studies can be used as guidelines for determining the factors might influence the university professors' productivity under this new situation of delivering the majority of course content online for the foreseeable future. Academic institutions administrators should carefully take into consideration the factors that might influence their academic faculty's staff level of health-related quality of life. 


\section{Acknowledgments}

We want to thank our dear participating professors for sharing their valuable time with us.

\section{Author contributions}

All authors contributed in the conceptual foundation of the study in terms of its rationale, design, data collection, analyses, discussion, and interpretation. All authors read and approved the final manuscript.

\section{Availability of data and materials}

The datasets used and/or analyzed during the current study are available from the corresponding author upon reasonable request.

\section{Conflict of interest}

The authors declare that they have no competing interests.

\section{Ethics approval}

This study was performed in line with the principles of the Declaration of Helsinki. Approval was granted by the Ethics Committee at Jordan University of Science and Technology, IRB approval number: \# 68/132/2020.

\section{Funding}

This study was directed by Jordan University of Science and Technology under project number 20200221. The funding agency had no any role in designing, conducting, or writing up the study.

\section{References}

[1] WHO. Statement on the second meeting of the International Health Regulations (2005) Emergency Committee regarding the outbreak of novel coronavirus (2019-nCoV). 2020.

[2] Adhikari SP, Meng S, Wu Y-J, Mao Y-P, Ye R-X, Wang Q$\mathrm{Z}$, et al. Epidemiology, causes, clinical manifestation and diagnosis, prevention and control of coronavirus disease
(COVID-19) during the early outbreak period: a scoping review. Infectious Diseases of Poverty. 2020;9(1):1-12.

[3] Malkawi SH, Almhdawi K, Jaber AF, Alqatarneh NS. COVID-19 Quarantine-Related Mental Health Symptoms and their Correlates among Mothers: A Cross Sectional Study. Maternal and Child Health Journal. 2020:1-11.

[4] Brooks SK, Webster RK, Smith LE, Woodland L, Wessely S, Greenberg N, et al. The psychological impact of quarantine and how to reduce it: rapid review of the evidence. The Lancet. 2020.

[5] Cladellas-Pros R, Castello-Tarrida A, Parrado-Romero E. [Satisfaction, health and work-related stress of the university professorship according to their contractual status]. Revista de salud publica (Bogota, Colombia). 2018;20(1):53-9.

[6] Dutta AP, Pyles MA, Miederhoff PA. Stress in health professions students: myth or reality? A review of the existing literature. Journal of National Black Nurses' Association : JNBNA. 2005;16(1):63-8.

[7] Carrillo-Gonzalez A, Camargo-Mendoza M, Cantor-Cutiva LC. Relationship Between Sleep Quality and Stress with Voice Functioning among College Professors: A Systematic Review and Meta-analysis. Journal of voice : official journal of the Voice Foundation. 2019.

[8] Kessler RC, Petukhova M, Sampson NA, Zaslavsky AM, Wittchen HU. Twelve-month and lifetime prevalence and lifetime morbid risk of anxiety and mood disorders in the United States. International Journal of Methods in Psychiatric Research. 2012;21(3):169-84.

[9] Stein MB, Roy-Byrne PP, Craske MG, Bystritsky A, Sullivan G, Pyne JM, et al. Functional impact and health utility of anxiety disorders in primary care outpatients. Medical Care. 2005;43(12):1164-70.

[10] Mackenzie S, Wiegel JR, Mundt M, Brown D, Saewyc E, Heiligenstein E, et al. Depression and suicide ideation among students accessing campus health care. The American Journal of Orthopsychiatry. 2011;81(1):101-7.

[11] Roest AM, Martens EJ, de Jonge P, Denollet J. Anxiety and risk of incident coronary heart disease: a metaanalysis. Journal of the American College of Cardiology. 2010;56(1):38-46.

[12] Mahan JD, Clinchot D. Why medical education is being (inexorably) re-imagined and re-designed. Current Problems in Pediatric and Adolescent Health Care. 2014;44(6):137-40.

[13] Almhdawi KA. Influencing Medical Students' Knowledge and Attitudes Related to Disability: A Randomized Controlled Trial. American Journal of Physical Medicine \& Rehabilitation. 2021.

[14] Green BNJTJotCCA. A literature review of neck pain associated with computer use: public health implications. 2008;52(3):161.

[15] Smith L, Louw Q, Crous L, Grimmer-Somers KJC. Prevalence of neck pain and headaches: impact of computer use and other associative factors. 2009;29(2):250-7.

[16] Chiu T, Ku W, Lee M, Sum W, Wan M, Wong C, et al. A study on the prevalence of and risk factors for neck pain among university academic staff in Hong Kong. 2002;12(2):77-91.

[17] Brailovskaia J, Cosci F, Mansueto G, Miragall M, Herrero $\mathrm{R}$, Baños RM, et al. The association between depression symptoms, psychological burden caused by Covid-19 and physical activity: An investigation in Germany, Italy, Russia, and Spain. 2021;295:113596.

[18] Redondo-Flórez L, Fernández-Lucas J, Clemente-Suárez VJJN. Cultural differences in stress-related psychological, 
nutrition, physical activity and oral health factors of professors. 2020;12(12):3644.

[19] Barkley JE, Lepp A, Glickman E, Farnell G, Beiting J, Wiet R, et al. The acute effects of the COVID-19 pandemic on physical activity and sedentary behavior in university students and employees. 2020;13(5):1326.

[20] Sirajudeen MS, Alaidarous M, Waly M, Alqahtani M. Workrelated musculoskeletal disorders among faculty members of college of Applied Medical Sciences, Majmaah University, Saudi Arabia: A cross-sectional study. International Journal of Health Sciences. 2018;12(4):18.

[21] Mudrak J, Zabrodska K, Kveton P, Jelinek M, Blatny M, Solcova I, et al. Occupational well-being among university faculty: A job demands-resources model. Research in Higher Education. 2018;59(3):325-48.

[22] Alavi SS, Abbasi M, Mehrdad R. Risk factors for upper extremity musculoskeletal disorders among office workers in Qom province, Iran. Iranian Red Crescent Medical Journal. 2016;18(10).

[23] Blatter B, Bongers P. Duration of computer use and mouse use in relation to musculoskeletal disorders of neck or upper limb. International Journal of Industrial Ergonomics. 2002;30(4-5):295-306.

[24] Silvian SP, Maiya A, Resmi A, Page T. Antecedents of work related musculoskeletal disorders in software professionals. International Journal of Enterprise Network Management. 2011;4(3):247-60.

[25] Ozer M, Altan L, Celik C, Okmen B. Prevalence of Neck Pain in Hospital Secretaries and Impact of Disability on Psychological State and Quality of Life. Austin Med Sci. 2016;1(2):1006.

[26] Darabi M, Macaskill A, Reidy L. A qualitative study of the UK academic role: positive features, negative aspects and associated stressors in a mainly teaching-focused university. Journal of Further and Higher Education. 2017;41(4):56680.

[27] Souza KR, Fernandez VS, Teixeira LR, Larentis AL, Mendonça ALO, Felix EG, et al. [Notebooks on health and work: diaries of public university professors]. Cadernos de Saude Publica. 2018;34(3):e00037317.

[28] Kermansaravi F, Navidian A, Navabi Rigi S, Yaghoubinia F. The relationship between quality of work life and job satisfaction of faculty members in Zahedan University of Medical Sciences. Global Journal of Health Science. 2014;7(2):228-34.

[29] Alves PC, Oliveira AF, Paro H. Quality of life and burnout among faculty members: How much does the field of knowledge matter? PloS One. 2019;14(3):e0214217.

[30] Faul F, Erdfelder E, Buchner A, Lang A-G. Statistical power analyses using $\mathrm{G}^{*}$ Power 3.1: Tests for correlation and regression analyses. Behavior Research Methods. 2009;41(4):1149-60.

[31] Al Sayah F, Ishaque S, Lau D, Johnson JA. Health related quality of life measures in Arabic speaking populations: a systematic review on cross-cultural adaptation and measurement properties. Quality of Life Research. 2013;22(1):213-29.

[32] Ware Jr JE, Kosinski M, Keller SD. A 12-Item Short-Form Health Survey: construction of scales and preliminary tests of reliability and validity. Medical Care. 1996:220-33.

[33] Patrick J, Dyck M, Bramston P. Depression Anxiety Stress Scale: is it valid for children and adolescents? Journal of Clinical Psychology. 2010;66(9):996-1007.

[34] Lovibond PF, Lovibond SH. The structure of negative emotional states: Comparison of the Depression Anxi- ety Stress Scales (DASS) with the Beck Depression and Anxiety Inventories. Behaviour Research and Therapy. 1995;33(3):335-43.

[35] Almhdawi KA, Kanaan SF, Khader Y, Al-Hourani Z, Almomani F, Nazzal M. Study-related mental health symptoms and their correlates among allied health professions students. Work. 2018;61(3):391-401.

[36] Vernon H, Mior S. The Neck Disability Index: a study of reliability and validity. Journal of Manipulative and Physiological Therapeutics. 1991.

[37] Shaheen AA, Omar MT, Vernon H. Cross-cultural adaptation, reliability, and validity of the Arabic version of neck disability index in patients with neck pain. Spine (Phila Pa 1976). 2013;38(10):E609-615.

[38] Craig CL, Marshall AL, Sjöström M, Bauman AE, Booth ML, Ainsworth BE, et al. International physical activity questionnaire: 12 -country reliability and validity. Medicine \& Science in Sports \& Exercise. 2003;35(8):1381-95.

[39] Citko A, Górski S, Marcinowicz L, Górska A. Sedentary lifestyle and nonspecific low back pain in medical personnel in north-east Poland. BioMed Research International. 2018;2018.

[40] Powell KE, Paluch AE, Blair SN. Physical activity for health: What kind? How much? How intense? On top of what? Annual Review of Public Health. 2011;32:349-65.

[41] Helou K, El Helou N, Mahfouz M, Mahfouz Y, Salameh P, Harmouche-Karaki M. Validity and reliability of an adapted arabic version of the long international physical activity questionnaire. BMC Public Health. 2017;18(1):49.

[42] Stoltzfus JC. Logistic regression: a brief primer. Academic emergency medicine : official journal of the Society for Academic Emergency Medicine. 2011;18(10):1099-104.

[43] Campolina AG, Lopez RVM, Nardi EP, Ferraz MB. Quality of life in a sample of Brazilian adults using the generic SF12 questionnaire. Revista da Associacao Medica Brasileira (1992). 2018;64(3):234-242.

[44] Mols F, Pelle AJ, Kupper N. Normative data of the SF-12 health survey with validation using postmyocardial infarction patients in the Dutch population. Quality of life research : an international journal of quality of life aspects of treatment, care and rehabilitation. 2009;18(4):403-14.

[45] Gandek B, Ware JE, Aaronson NK, Apolone G, Bjorner $\mathrm{JB}$, Brazier JE, et al. Cross-validation of item selection and scoring for the SF-12 Health Survey in nine countries: results from the IQOLA Project. International Quality of Life Assessment. Journal of Clinical Epidemiology. 1998;51(11):1171-8.

[46] Ware JE, Jr., Gandek B, Kosinski M, Aaronson NK, Apolone G, Brazier J, et al. The equivalence of SF-36 summary health scores estimated using standard and country-specific algorithms in 10 countries: results from the IQOLA Project. International Quality of Life Assessment. Journal of Clinical Epidemiology. 1998;51(11):1167-70.

[47] Gratz KL, Tull MT, Richmond JR, Edmonds KA, Scamaldo $\mathrm{KM}$, Rose JP. Thwarted belongingness and perceived burdensomeness explain the associations of COVID-19 social and economic consequences to suicide risk. Suicide \& LifeThreatening Behavior. 2020;50(6):1140-8.

[48] Reger MA, Stanley IH, Joiner TE. Suicide Mortality and Coronavirus Disease 2019-A Perfect Storm? JAMA psychiatry. 2020.

[49] da Silva Souza AP, Silva MRM, Da Silva ABJ, de Lira PC, da Silva JML, da Silva ML, et al. Anxiety Symptoms in University Professors during the COVID-19 Pandemic. 2020;14(7):1-3. 
[50] Moksnes UK, Eilertsen MB, Ringdal R, Bjørnsen HN, Rannestad T. Life satisfaction in association with self-efficacy and stressor experience in adolescents - selfefficacy as a potential moderator. Scandinavian Journal of Caring Sciences. 2019;33(1):222-30.

[51] Hewett ZL, Pumpa KL, Smith CA, Fahey PP, Cheema BS. Effect of a 16-week Bikram yoga program on perceived stress, self-efficacy and health-related quality of life in stressed and sedentary adults: A randomised controlled trial. Journal of Science and Medicine in Sport. 2018;21(4): 352-7.
[52] Hampton D, Culp-Roche A, Hensley A, Wilson J, Otts JA, Thaxton-Wiggins A, et al. Self-efficacy and Satisfaction With Teaching in Online Courses. Nurse educator. 2020.

[53] Almhdawi KA, Mathiowetz V, Al-Hourani Z, Khader Y, Kanaan SF, Alhasan M. Musculoskeletal pain symptoms among allied health professions' students: Prevalence rates and associated factors. Journal of Back and Musculoskeletal Rehabilitation. 2017;30(6):1291-301. 